\title{
DIMENSIÓN DEL DISCURSO ARGUMENTATIVO
}

\section{Lázaro CARRILLO GUERRERO}

\author{
Universidad de Granada \\ lzro@msn.com
}

Resumen: La argumentación es un discurso que subyace en todo uso de la lengua, y por tanto en la acción y fuerza ilocutiva que despliega cualquier tipo de texto. Donde el discurso y la textualidad se construyen para ser dirigidos a un ethos, de acuerdo a un propósito y sosteniendo una tesis.

\begin{abstract}
Argumentation is a discourse type that underlies every language use, and therefore it underlies the action and ilocutive force that it is displayed in any text type. Here, discourse and textuality are produced in order to be addressed to the ethos, in accordance with an aim and backing a thesis.
\end{abstract}

Palabras clave: Retórica. Informar. Convencer. Demostrar. Persuadir.

Key Words: Rhetoric. To inform. To convince. To Demonstrate. To Persuade. 


\section{INTRODUCCIÓN}

La lengua despliega una dimensión argumentativa ya que su uso tiene un rol intencionado, y éste existe de acuerdo a las relaciones que se establecen entre los interlocutores. Pero nuestra conducta lingüística es algo más que lengua, es discurso. Y todo discurso implica diálogo. Pues usar la lengua es establecer una relación de diálogo, donde el propósito fundamental del hablante es formular un mensaje para que funcione con efectividad como acto comunicativo, teniendo en cuenta las características del auditorio y de la situación.

Desde este planteamiento, la argumentación no es un género determinado del discurso, para unos usos específicos u ocasionales, sino que es un discurso que subyace en la base de todo acto de habla. Esta dimensión argumentativa se sitúa en las propiedades interaccionales o de diálogo que todo acto comunicativo y toda codificación lingüística tiene. Pero además, obedece a unos esquemas mentales: cognitivos (representaciones) y lógicos (construcciones), que van en función de lo que opera sobre nosotros al escuchar, y lo que opera sobre nosotros al enunciar.

Por todo ello, entendemos que la conducta lingüística es argumentativa: siempre utilizamos la lengua en interacción, marcando una relevancia informativa, directa o inferencial con respecto al otro interlocutor, y con una determinada fuerza ilocutiva orientada por la lógica de lo probable. Elegimos unas palabras y las organizamos en un discurso para hacer adherirse al destinatario a unas ideas o a unas convenciones. La argumentación es algo natural e inherente a todos nuestros discursos. Es la forma esencial y común que expresa nuestras relaciones con el mundo. En este sentido, todo discurso es argumentativo, ya que se trata de la acción de la lengua con respecto al ser $\mathrm{y}$ a sus mundos posibles.

\section{ACCIÓN ARGUMENTATIVA}

Popper (1979: 116-120) establece una jerarquía de funciones de la lengua («Argumentative, Descriptive, Signalling, Expressive»), donde las más importantes son la función descriptiva y la argumentativa, estando las otras dos en un nivel más bajo y siendo comunes al lenguaje humano y animal. Esta jerarquía presupone que una función más alta coexiste con las funciones que hay por debajo de ella, pero una función más baja no implica necesariamente la existencia de una función más alta. Así, la función argumentativa presupone la función descriptiva, ya que los argumentos tratan fundamental- 
mente de descripciones. Faigley y Meyer (1983: 308), desde una perspectiva pragmática, resaltan que un argumento puede utilizar descripciones, narrativas personales y procesos evaluativos.

Desde estas perspectivas, entendemos que el discurso argumentativo es el que contribuye a la interacción humana, y aunque la superficie de los textos pueda ser narrativa, descriptiva, explicativa, procedimental, etc., su dimensión interna o profunda es argumentativa. Por tanto, un texto argumentativo puede caracterizarse por el proceso de interacción ${ }^{1}$ (desde unas posiciones o puntos de vista, construyendo una realidad en unas estructuras lingüísticas) que implica cualquier estructura narrativa, descriptiva, explicativa, etc. En este proceso de interacción, las estructuras lingüísticas textuales contribuyen a un movimiento discursivo que va desde una posición de salida (datos, premisas) a otra de llegada (conclusiones, resultados). Pero este movimiento (donde el proceso de inferencia tiene una relevancia primordial) se sirve de los diferentes procedimientos y estructuras textuales.

En el siguiente texto ${ }^{2}$ (n. ${ }^{\circ} 1$ ), además de observar que el uso de la lengua tiene un rol intencionado, y éste existe de acuerdo con las relaciones que se establecen entre los interlocutores, desplegándose en ello la dimensión argumentativa de la lengua:

[Extracto de un programa de radio, donde el locutor, Bob Grant (uno de los más populares y controvertidos locutores de los Estados Unidos), recibe las llamadas de los oyentes para que den su opinión. El tema del programa es a favor del racismo tan abiertamente que muchos oyentes afirman no tomárselo en serio]

BOB GRANT: Hello, Joe, you're on WABC, what's on your mind?

FIRST CALLER: Yeah, how are you doing? I wanted to talk about a very sympathetic piece in yesterday's TIMES by Ira Berkow. It's about a sub-humanoid by the name of Ron L. Williams...

BOB GRANT: Ah! Yeah, Ron L. Williams! Oh, he's going to get a chance to play basketball!

FIRST CALLER: The background: this kid's eighteen years old, 29 points a game, honorable mention in the All-American team. The kid was in reform

\footnotetext{
${ }^{1}$ Los textos argumentativos son, explícita o implícitamente, dialogales, es decir, son siempre el lugar de una visión contradictoria del mundo, y se organizan alrededor de dos tesis afrontadas (incluso si, por unas razones estratégicas, una de entre ellas puede estar ocultada). De modo que plantean siempre el problema del estatus de la palabra del otro (Boissinot, 1992: 12-13).

2 Speak Up, 1995, n. ${ }^{\circ} 123$, p. 36. Barcelona: RBA Revistas SA.
} 
school, he had gotten into trouble before and he got another chance. He came from a typical background. His mother was a drug addict, his father was shot when he was three years old and killed by his mother's boyfriend. Supposedly, the kid had turned himself around, became an honors student, top 10 per cent of his class, he'd taken advanced placement courses, had met President Bush when Bush went to speak at his school, he was one of the top 10 kids in the whole school. So what happens to this kid?. He's all set to go to Ohio University on a full scholarship, which - how many people in this country can afford that type of tuition? And what happens? He gets busted for selling crack. Now that's not bad enough, it's stupid enough. His reason for selling crack was that he had to pay for abortions for both of the young women who were impregnated by him.

BOB GRANT: Well, that's the only good thing he did was he paid for abortions. Better that they had the abortions than produce other anti-social, miscreant prime like him.

FIRST CALLER: Hah, hah, hah! Primates! That's perfect! That's a perfect description! If you take a look at his picture, he looks like... he's standing... he's sitting on a stairwell, but it looks like it could easily be the monkey cage at the Bronx Zoo...

BOB GRANT: But he's very relaxed because there's graffiti all over the wall and he relaxes when there's graffiti and dirt around him!

2ND CALLER: I don't know, but I've also come to the conclusion that earth's endangered species is not the spotted owl, nor the humpback whale, it is the white race. But there is an organisation fighting for us and it is called the National Alliance, headed by the honorable Dr. William Pearce in Hillsboro, West Virginia; P. O. Box 90, 24946. Hail victory! Blood and soil!

Podemos estudiar cómo el interlocutor First Caller, en su segunda intervención, mediante un procedimiento narrativo asienta el movimiento argumentativo hacia la conclusión. Además, este mismo interlocutor, en su primera intervención, hace una afirmación concluyente: It's about a sub-humanoid by the name of Ron L. Williams..., para luego exponer las premisas que la apoyan, es decir, la realidad que él construye para esa conclusión. Esto último ilustra cómo el discurso argumentativo no está apremiado por ciertos condicionantes en su desarrollo, como, por ejemplo, el discurso narrativo o explicativo. En el narrativo, por regla general, la solución del conflicto o de las situaciones creadas no puede ir antes de esta trama narrativa donde se ubican ${ }^{3}$.

${ }^{3}$ La narración tiene que ver con el proceso cognitivo de la percepción en el tiempo (Werlich, 1982: 39), lo que hace que, por regla general, sea más fácil la completa comprensión de la información. 
Sin embargo, el discurso argumentativo puede presentar la conclusión antes de los argumentos que la apoyan.

De acuerdo con Adam (1997: 103-4), la argumentación puede ser abordada en dos niveles:

a) El nivel del discurso y la interacción social, donde un interlocutor construye una representación discursiva, queriendo modificar la representación de un interlocutor a propósito de un discurso dado, y donde el objetivo argumentativo se puede considerar como un objetivo ilocutivo.

b) El nivel de la organización pragmática de la textualidad, donde se considera la existencia, en los interlocutores, de unas representaciones prototípicas relativas a uno o varios esquemas argumentativos, con una organización secuencial. Aquí, la relación Premisas (Argumentos/Datos/Razones) $\rightarrow$ Conclusión puede considerarse como una secuencia de base.

Entendemos que la dimensión del discurso argumentativo se extiende, a través de estos dos niveles (discurso e interacción social, y organización pragmática de la textualidad), por todo tipo de texto. Estos dos niveles, en una relación de inclusión (el uno incluye o implica el otro), vienen a actuar en la misma acción discursiva: intervenir sobre las opiniones, actitudes, o comportamientos del interlocutor o de un auditorio, haciendo aceptables o creíbles unas conclusiones que se apoyan sobre unos argumentos, datos o razones. Ello trae consigo que si se aceptan las conclusiones, también se aceptan los argumentos, los datos o las razones. Según Adam (1997: 104), a diferencia de las premisas, lo característico de una conclusión es servir, a su vez, en el discurso, de elemento de apoyo (como argumentos, datos o razones) para otras conclusiones.

Desde esta perspectiva, creemos que la acción y fuerza ilocutiva que despliega un texto narrativo, descriptivo, explicativo, procedimental, etc., viene dada por su dimensión argumentativa y fuerza retórica. En ellos, siempre hay una acción argumentativa, con un objetivo ilocutivo y una organización pragmático-textual argumentativa. Así, por ejemplo, Antaki (1994) considera que el discurso explicativo (tratado como «causal explanation») tiene la función de clarificar, elaborar o justificar a través del argumento. Golder y Coirier (1996: 280) afirman que toda argumentación tiene un componente de explicación, la cual está fundada únicamente en la causalidad. Y Nielsen (1996: 343) concluye que el nivel estructural de un argumento puede presentarse en dos tipos básicos de relaciones: 
1) La relación causal que conecta dos contenidos proposicionales.

2) La relación explicativa, en la cual un contenido proposicional es enlazado al acto ilocutivo de otro contenido proposicional.

Ella afirma que al operar la relación explicativa en el nivel ilocutivo, ésta pertenece a una relación argumentativa.

Entendemos que este componente explicativo, asociado con el carácter heterogéneo de los textos, es una muestra de cómo las diferentes acciones textuales, operando en el nivel ilocutivo del discurso, tienen una dimensión argumentativa. De modo que un texto puede presentar en su superficie una estrategia narrativa, descriptiva, etc., pero en el nivel ilocutivo del discurso siempre hay en ese texto, explicita o implícitamente, una fuerza retórica y argumentativa ${ }^{4}$.

La figura 1 puede representar nuestro planteamiento. En ella se representa la dimensión argumentativa del discurso. Donde la acción argumentativa ejerce una amplitud ilocutiva en todo tipo de acción textual. Y donde actúa siendo central a todo tipo de texto y discurso:

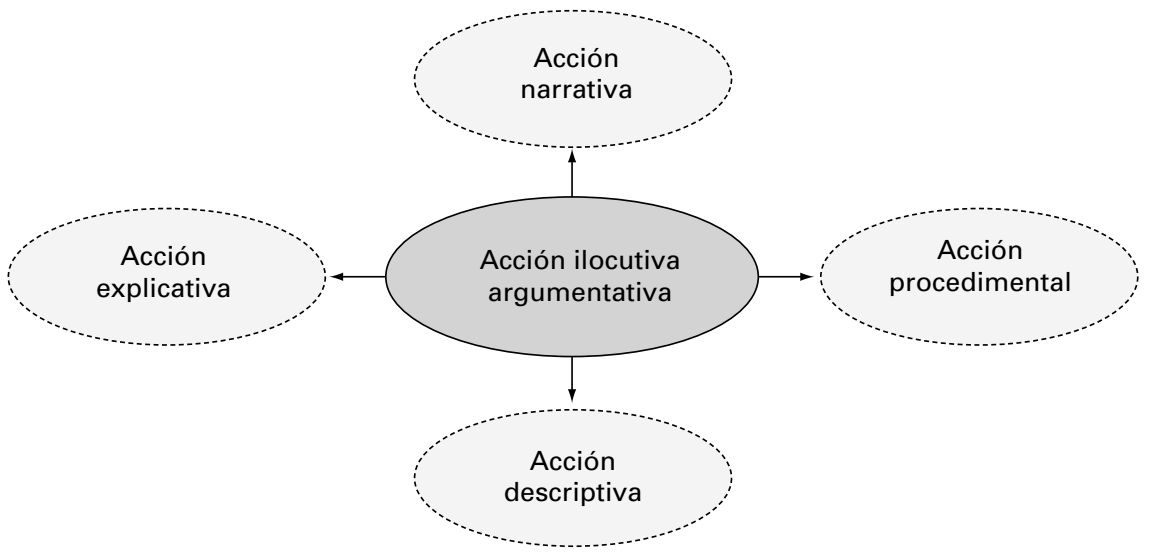

FIgURA 1. Dimensión del discurso argumentativo.

\footnotetext{
${ }^{4}$ Nuestro planteamiento difiere de aquél que podría dar a entender que un texto es argumentativo sólo si contiene explícitamente unos razonamientos, una tesis, unos datos que los justifiquen, y unas conclusiones. Por otro lado, se podría hablar de actos ilocutivos colaterales, es decir, de actos de habla no argumentativos (como pueden ser los expresivos y declarativos) que forman parte de la fuerza argumentativa, haciéndola más eficaz (Eemeren y Grootendorst, 1984: 106 y passim; Lo Cascio, 1998: 118). O de argumentación de base y argumentación periférica (Lo Cascio, 1998: 143). Adam (1985) habla de textos explicativo-argumentativos, argumentativos-narrativos, etc., como unos tipos de textos intermediarios.
} 
En la figura 1 se representan las acciones narrativa, explicativa, descriptiva y procedimental, entendiendo que éstas representan, simbólicamente, a todas las acciones (de acuerdo con las distintas tipologías de texto y discurso) que las estrategias interaccionales de los interlocutores requieran en su acción ilocutiva-argumentativa. Así, las diferentes acciones narrativa, descriptiva, explicativa, procedimental, etc., desarrollarán, por cuestión del tipo de género al que pertenecen, unas secuencias textuales y unas funciones características propias, y ahí se definirían sus respectivas acciones. Pero creemos que todas ellas desarrollan también, de una forma o de otra, una acción ilocutiva, una acción argumentativa (en sus dos niveles, expuestos anteriormente), basada en las diferentes posiciones o puntos de vista sobre la construcción de la realidad $^{5}$. Por ello, entendemos que estas acciones, correspondientes a unos tipos de textos o de discursos y a unas estructuras genéricas, en su base, están al servicio de una acción mayor: la acción argumentativa ${ }^{6}$. Teniendo todas ellas una orientación argumentativa:

La estructura del texto es gramatical, por las reglas que lo sostienen estructuralmente, pero su significado es retórico, argumentativo por más señas, al depender de principios organizativos (Martínez-Dueñas, 2002: 23).

Así, por ejemplo, la narración o la acción narrativa, además de formar una unidad con su propia estructura interna, la consideramos como parte de otro proceso en marcha. Parte de un modelo más grande: una interacción, donde las proposiciones no son neutrales, sino que reflejan una actitud hacia lo probable, lo deseable, y unos propósitos en su proceso de comunicación, y donde el destinatario infiere (de acuerdo con su situación) ostensivamente unos significados y unas conclusiones. Es decir, forma parte de la acción argumentativa. Y, por ejemplo, lo relevante de la lectura o la recitación de una poesía es que conduce a inferir unas conclusiones acerca del tema que trata y a través de las premisas o datos que emplea, al igual que sucede con la lec-

\footnotetext{
5 Por ejemplo: «Mumby's $(1987 ; 1988)$ analysis of organizational storytelling is a good example of how stories as discursive practices are powerful devices for structuring organizational reality. [...] Collinson (1988) provides an interesting participant-observer study of social interaction in an engineering plant. He examines the ways in which the exclusively male, working class workforce employs humor as a discursive practice that functions in multiple ways to: a) resist management ideology; b) produce conformity to working class norms of masculinity; and c) control fellow workers who shirk their job responsibilities» (Mumby y Clair, 1997: 187-191).

${ }^{6}$ La utilización del ejemplo ha sido una práctica tradicional en la inserción de una (micro)/secuencia narrativa en la argumentación. En la retórica clásica, la narración y la descripción han sido unas herramientas de la argumentación. La narración siendo parte de la dispositio, y la descripción formando parte de los topoi.
} 
tura de una novela, o con la experiencia de ver una película. E incluso tomando el texto siguiente (n. 2 ):

[Receta de cocina]

\section{RIBBLE VALLEY FRIED TROUT}

4 medium sized trout, 4 oz oatmeal, 4 oz butter, 1 bunch of fresh parsley, salt and pepper, 2 lemons.

Clean trout, scale \& remove fins, tails, etc. Do not split open. Dip all over in seasoned oatmeal. Heat some butter in a large frying pan. When hot put in trout and fry until golden brown. Cut parsley finely and quarter the lemons. Sprinkle generously over the trout and serve with creamed potatoes and mushrooms.

\section{TRADITIONAL LANCASHIRE RECIPES}

como un ejemplo, aparentemente, muy alejado de nuestro planteamiento ya que se trata de una receta culinaria, podemos observar, en este texto procedimental (o instructivo), una acción ilocutiva-argumentativa en los siguientes términos:

- Un modo imperativo:

Clean trout, scale \& remove fins, tails, etc. Do not split open. Dip all over in seasoned oatmeal. Heat some butter in a large frying pan. When hot put in trout and fry until golden brown. Cut parsley finely and quarter the lemons. Sprinkle generously over the trout and serve with creamed potatoes and mushrooms,

que expresa unos consejos, con la intención implícita de beneficiar al receptor en la realización de este plato gastronómico que, además, va a constituir un acto social, tal como lo indica, implícitamente, la expresión: ....and serve with creamed potatoes and mushrooms.

- Una sucesión lógica en el contenido del mensaje, a través de unas relaciones estructurales paratácticas y logico-semánticas de elaboración (expansión), en yuxtaposición:

- Clean trout, scale \& remove fins, tails, etc. Do not split open. Dip all over in seasoned oatmeal.

- Heat some butter in a large frying pan. When hot put in trout and fry until golden brown. 
- Cut parsley finely and quarter the lemons. Sprinkle generously over the trout and serve...

- Una conclusión implícita (más bien modalizadora), e inicial, So you will have a delicious Ribble valley fried trout, y caracterizada por:

- Apoyarse en un movimiento argumentativo (o en unas premisas) constituido por: a) la intención implícita de beneficiar al auditorio, y éste beneficiarse de ello mediante su acto perlocutivo, b) la sucesión lógica del contenido del mensaje, desplazándose hacia la finalidad concluyente: and you will have a delicious Ribble valley fried trout.

- Estar situada en el discurso, en la macro-argumentación, de este texto.

Por otro lado, Kress (1989; en Andrews, 1992: 122) tendría una posición crítica frente a la nuestra (o viceversa). Él no acepta el considerar a la narrativa como el vehículo y a la argumentación como el instrumento o el tenor de la expresión. Y sugiere que la narrativa y el argumento son dos modos muy diferentes de organizar el texto verbal o visual. Andrews (1992: 122), de acuerdo con los planteamientos de Kress y los suyos propios, concluye que el argumento es una forma progresiva, ya que es un agente de cambio, mientras que la narrativa es conservativa, ya que el cierre viene desde dentro. Cuando el cierre ocurre en el argumento, éste viene impuesto desde fuera. Andrews (1992) añade que esta distinción no significa que la narrativa sea una forma cultural inferior al argumento.

La dimensión argumentativa tiene su presencia en unas estructuras textuales heterogéneas. Entendiendo que la homogeneidad en el texto es la excepción, y que la heterogeneidad es una característica no sólo del texto, sino del lenguaje humano. Desde esta posición, Adam (1997) basa su tipología de textos en la prominencia de una secuencia dominante sobre otra dominada, en una estructura secuencial heterogénea. Así, la secuencia dominante argumentativa (págs. 103-126), junto con los prototipos narrativo, descriptivo, explicativo y dialogal, tendría, en un texto heterogéneo, la siguiente estructura prototípica ${ }^{7}$ (pág. 118):

7 Adam (1997: 34) plantea que un texto es una estructura jerárquica compleja, comprendiendo $n$ secuencias -elípticas o completas-del mismo tipo o de tipos diferentes. 
Tesis anterior + Datos (Premisas) - Proceso de inferencias - Restricción $\rightarrow$ Conclusión (nueva tesis) $\begin{array}{lllll}\text { P. arg. } 0 & \text { P.arg. } 1 & \text { P. arg. } 2 & \text { P. arg. } 4 & \text { P. arg. } 3\end{array}$

El esquema de base de tres macro-proposiciones (P. $\arg .1,2$ y 3$)$ toma apoyo explícito de la $P$. arg. $O$ (tesis anterior) en el caso particular de la refutación. La restricción (P. arg. 4) -refutación o excepción-modaliza el pasaje de los datos a la conclusión. Y en el proceso de inferencias (P. arg. 2) se sitúan la garantía y el apoyo. Este esquema prototípico no es de un orden lineal inflexible: la nueva tesis (P. arg. 3) puede ser formulada de entrada, y retomada o no por una conclusión que la repite al final de la secuencia, y la tesis anterior (P. arg. O) puede ser sobreentendida. Adam formula esta hipótesis secuencial, considerando la variedad de discursos y textos argumentativos, y basándose en la posibilidad de reconocimiento, por parte de los interlocutores, de una forma prototípica de secuencia argumentativa de base. Esta secuencia de base (Toulmin, 1958) es la puesta en relación de unos datos con una conclusión. Y esta puesta en relación puede estar fundada implícita o explícitamente (garantía o apoyo) o contrariada (refutación o excepción). Si los datos constituyen el elemento que está más a menudo explícito, el apoyo está muy a menudo implícito, y los otros componentes se sitúan entre estos dos polos de implicitación y de explicitación. Con todo esto, el texto argumentativo, según Adam (1997), será el que tenga esta estructura prototípica como secuencia dominante entre las secuencias narrativas, descriptivas, explicativas y dialogales ${ }^{8}$ que se den en la heterogeneidad del texto en cuestión.

Adam (1997), dentro de la heterogeneidad, relega la secuencia argumentativa en los diferentes tipos de textos, narrativo, descriptivo, explicativo y dialogal, a una secuencia dominada y al servicio de cada uno de ellos con sus respectivas secuencias dominantes. A este respecto, el planteamiento de texto argumentativo de Adam (1997), de acuerdo con la heterogeneidad secuencial de los textos, nos parece acertada en parte, pero con la salvedad de no situarse en el nivel del texto ${ }^{9}$, sino en el de la secuencia. Nuestro planteamiento es distinto, como ya lo hemos mostrado anteriormente: independientemente de esa relación textual de secuencias, la acción argumentativa,

\footnotetext{
${ }^{8}$ La concepción de secuencialidad de Adam (1997: 196) se apoya en el hecho de que existen unos esquemas prototípicos abstractos, culturalmente transmitidos, y ello confiere al discurso una cierta estructura composicional.

9 Adam (1997), basándose en la ambición de M. Bajtín de fundar una «sintaxis de grandes masas verbales», propone situar esta sintaxis en el nivel de la secuencia, y no en el nivel del texto, demasiado complejo y heterogéneo.
} 
basada en unos niveles ilocutivo e inferencial-concluyente, está en la base de toda tipología textual o discursiva. La acción de estos dos niveles está siempre presente en los textos y discursos.

Así, Virtanen (1992) considera al discurso argumentativo como un tipo de discurso fuerte, ya que muestra una máxima realización a través de los diferentes tipos de texto. En contraste, considera al texto narrativo como un tipo de texto fuerte y flexible, ya que puede realizar diferentes tipos de discursos (narración, instrucción, descripción, exposición o argumentación). Él añade que el discurso es fundamentalmente persuasivo, y el tipo de discurso argumentativo (que puede tomar fácilmente la forma de cualquier tipo de texto) conectado con la función persuasiva del discurso, es, por lo tanto, frecuentemente representado en los textos, y expuesto a través de un abanico de diferentes tipos de textos, donde no se necesita ninguna señal de argumentación. Además, Virtanen añade que la argumentación es relativamente un tipo de texto débil, pero un tipo de discurso prototípico, al igual que la narración es un tipo de texto prototípico y un tipo de discurso débil. A veces, el tipo de discurso y el tipo de texto pueden coincidir. Pero, frecuentemente, un tipo de texto es usado para servir a otro tipo de discurso distinto.

Sin embargo, para Golder (1996: 197) no existe un texto argumentativo definido por entidades lingüísticas definitivamente fijado, sino un discurso argumentativo que se caracteriza por las huellas de las operaciones de justificación y negociación, y ambas dependiendo de la situación.

Para nosotros, construir un texto es argumentar. Y en ello intervienen, en una situación discursiva, numerosos procesos en consonancia con dos dimensiones: a) la negociabilidad retórica y gramatical del significado; y b) la intervención de los interlocutores con sus ideas y creencias. En el texto ${ }^{10}$ siguiente (n. $\left.{ }^{\circ} 3\right)$ :

[En la celebración festiva de una boda, los novios, subidos en una tarima, se dirigen a los invitados, quienes, estando de pie, están en un ambiente de fiesta]

FREDERICK: My lords, ladies and gentlemen - please charge your glasses. First, and rather unusually, we have... the bride. [Hay aplausos]

CARRIE: Thank you. First of all I'd like to thank all of you who've flown in from the States. I'm really touched. And as for the rest of you - I would have

10 De la película Four Weddings and a Funeral, dirigida por Mike Newell, 1994, Polygram Film Production $\mathrm{GmBH}$. 
thought the fact that lots of frightful Americans were flying in was the perfect excuse for staying away - so I thank you too. [Charles la mira con amor]

CARRIE: If my darling Dad had been here today, he would have been speaking now - and I know what he would have said - 'Great dress, babe, but why the hell are you marrying the stiff in the skirt?' [Hay alguna risa entre los invitados]

CARRIE: And I would have given him the same answer that I give you - because I love him. As John Lennon said, who died the same year as my Dad, 'Love is the answer - and you know that for sure.' [Carrie besa a Hamish, y hay aplausos]

CARRIE: O, and one more thing - someone here told me confidentially that if things with Hamish didn't work out, that he would step in. I just wanted to say, 'thanks and I'll keep you posted.' [Hamish la mira riéndose, y se oye un «bravo» entre el público]

FREDERICK: Now, my lords, ladies and gentlemen, Sir Hamish Banks.

[Hamish, debido a su experiencia y a su posición social, es afable y seguro de sí mismo]

HAMISH: Anyone involved in politics over the past twenty years has got used to being upstaged by a woman. But I didn't expect it to happen to me on my wedding day. However I must also say that I'm quite happy to be upstaged by this woman for the rest of my life.

[Se oye un ruido al final, de alguien que cae al suelo]

HAMISH: O dear, is that some barracking at the back - again, something we politicians are used to.

Podemos observar, una vez más, estas dos dimensiones. Carrie, dirigiéndose a un auditorio presente y partícipe de su boda, elabora un discurso donde hay un movimiento argumentativo alrededor de una conclusión latente: 'Love is the answer - and you know that for sure.'. Pero, principalmente, en todo su discurso sobresalen:

- La negociabilidad retórica y gramatical, a través de una organización sintáctica y estructural y un dirigirse a un auditorio, como por ejemplo:

Thank you. First of all I'd love to thank all of you who've flown in from the States. I'm really touched. And as for the rest of you...

- La intervención de sus ideas y creencias, y donde realmente se centra la intencionalidad de su discurso, como por ejemplo: 
If my darling Dad had been here today, he would have been speaking now and I know what he would have said - 'Great dress, babe, but why the hell are you marrying the stiff in the skirt?'... 'Love is the answer - and you know that for sure.'...

Beale (1987: 31 y sigs.) plantea que su clasificación de modos del discurso (discurso narrativo, dramático), y estrategias del discurso (genérico, dialéctico, estilístico, modal) son unas formas y métodos de presentar y realizar el discurso, más bien que unas razones. Y partiendo de que en las diferentes situaciones se puede elegir una forma u otra, Beale pone por ejemplo que ante la tarea de defender un punto de vista, un autor puede elegir presentar ese punto de vista de una forma muy directa, ofreciendo una serie de «buenas razones» para su validez; o el autor puede elegir «contar una historia» que ilustra de forma gráfica y altamente conmovedora la validez de la posición. Pero el autor, también, puede elegir contar la historia de cómo ha llegado a ese punto de vista, de cómo la experiencia forzó y apoyó el reconocimiento de su poderosa verdad.

Entendemos que son, pues, opciones retóricas a disposición de la argumentación, como lo son las distintas acciones narrativa, descriptiva, explicativa, procedimental, etc.

Por otro lado, el triángulo comunicativo que Kinneavy (1971) aplica al análisis del discurso, nos puede servir para contrastar nuestro planteamiento. Kinneavy (1971: 36), siguiendo la tradicional clasificación del discurso (narración, exposición, argumentación y descripción), la modifica a cuatro modos (narración, clasificación, descripción y evaluación), pero sin una aplicación a su triángulo de la comunicación (codificador, descodificador, señal, realidad). Considerando que el término modos ha sido tradicionalmente considerado como formas del discurso, o en literatura como géneros y tipos, Kinneavy lo define como formas de considerar la realidad, es decir, cómo la naturaleza de la realidad está siendo referida y en definitiva cómo está siendo construida. Frente a ello, y sin detrimento de esta clasificación, nuestro planteamiento considera que la realidad es construida mediante la acción de argumentar, y que esta acción está presente y está en la base de cualquier forma o tipo de referencia a la realidad, bien sea de forma narrativa, clasificativa, descriptiva o evaluativa. Kinneavy (págs. 60-61), sobre los cuatro componentes del triángulo (codificador, descodificador, señal, realidad), establece los propósitos o intenciones del discurso. Entendiendo por éstos, los propósitos o intenciones que los humanos, entre sí, pueden lograr en su uso de la lengua. Así, si el proceso de utilización de la lengua tiene un énfasis en el co- 
dificador o descodificador habrá un discurso de persona que será respectivamente expresivo o persuasivo; si el énfasis es en la realidad, habrá un discurso referencial (dividido en científico, informativo y exploratorio); si el énfasis es en el producto mismo de la lengua o señal, habrá un discurso producto que será literario. Frente a ello, nuestro planteamiento también considera que, sin detrimento de esta clasificación, los propósitos o intenciones que se construyen mediante las estructuras lingüísticas (producto) son realizados con una acción argumentativa interpersonal (codificador, descodificador) y en una construcción de la realidad (referencia). Así pues, esta acción está presente y está en la base de cualquier propósito expresivo, persuasivo, referencial o literario.

El texto anterior (n. ${ }^{\circ}$ 3) nos muestra, claramente, cómo la acción argumentativa es interpersonal (entre hablante y auditorio), y cómo en ella se ubica la construcción de la realidad, donde:

- Ya hay una realidad:

If my darling Dad had been here today, he would have been speaking now and I know what he would have said - 'Great dress, babe, but why the hell are you marrying the stiff in the skirt?'

Que Carrie construye, actualiza, con estas palabras, pero que su auditorio puede haberla construido, virtualmente, de otra forma.

- Con esta realidad que Carrie actualiza verbalmente, ella conduce, intencionadamente (para convencer), a su auditorio a una conclusión determinada:

And I would have given him the same answer that I give you - because I love him. As John Lennon said, who died the same year as my Dad, 'Love is the answer - and you know that for sure.'

Y que puede ser similar o diferente a la/s conclusión/es que, virtualmente, hubieran construido su auditorio.

La dimensión del discurso implica tres importantes factores (Dijk, 1997: 2):

a) El uso de la lengua.

b) La comunicación de creencias.

c) La interacción en situaciones sociales. 
Y entendemos que la combinación y la utilización de estos tres factores las realiza la acción retórica del discurso. Esta acción retórica utiliza la lengua y la adapta para poner en interacción (mediante unos principios retóricos) unas creencias con otras, unas posiciones o puntos de vista con otros. Esta acción comunicativa e interaccional proyecta en el uso de la lengua una dimensión argumentativa que está en la base de esa relación mutua que todas las conductas lingüísticas tienen unas con otras. Esta relación mutua requiere la acción estratégica del uso de la lengua en una situación de producción y entendimiento que requiere, además, unos procesos mentales y representaciones sociales. Por ello, definimos la dimensión del discurso argumentativo como la dimensión de la acción y de la base interaccional y dialogal del discurso. Pero una acción situada, local o globalmente, en una perspectiva o realidad social, política y cultural. Así, pues, la dimensión del discurso argumentativo es una dimensión retórica, basada en el principio dialogal de la lengua. Principio sobre el que se asienta la posición del discurso argumentativo tal como la define Moeschler (1985):

Un discurso argumentativo [...] se sitúa siempre en relación a un contra-discurso efectivo o virtual. [...] Defender una tesis o una conclusión viene a ser, siempre, defenderla contra otras tesis o conclusiones (Moeschler, 1985: 47; en Adam, 1997: 118; traducción nuestra).

Y por tanto, donde un texto argumentativo trae a primer plano el sistema retórico de la lengua, un sistema entre el hablante y su auditorio, y unas características propias de textualidad.

Si bien cada tipo de discurso hace intervenir unos elementos particulares, todo discurso está comprometido en la argumentación, en cuanto que éste intenta conducir al auditorio al mensaje que el hablante está comunicando, y mostrar que:

a) lo que se dice es justificable,

b) hay buenas razones y datos que apoyan lo que se dice,

b) el hablante merece confianza en lo que está diciendo,

c) ello ofrecerá algún beneficio al auditorio ${ }^{11}$.

Es decir, el discurso argumentativo requiere una construcción cognitiva entre los interlocutores, y una traducción lingüística de este proceso mental.

11 Son consideraciones clásicas. 
Entendemos que ésta es la base de la dimensión argumentativa de la lengua. Y el ejemplo anterior, en el texto n. ${ }^{\circ} 3$, nos lo ha mostrado en ese juego de acción lingüística y acción cognitiva que hay entre Carrie y su auditorio, frente a la conclusión que se puede inferir de su boda con Hamish:

Carrie construye, cognitivamente, con respecto a su auditorio, una realidad que ella traduce lingüísticamente, y cuyo movimiento argumentativo lo podemos escalonar en cuatro pasos (o movimientos):

1) If my darling Dad had been here today, he would have been speaking now

2) - and I know what he would have said - 'Great dress, babe, but why the hell are you marrying the stiff in the skirt?'

3) And I would have given him the same answer that I give you - because I love him.

4) As John Lennon said, who died the same year as my Dad, 'Love is the answer - and you know that for sure.'

para conducir a su auditorio a un proceso (también cognitivo) ostensivo-inferencial y dar relevancia a una implicación semántico-pragmática en un modo interrogativo y declarativo:

'... why the hell are you marrying the stiff in the skirt?' ...'Love is the answer - and you know that for sure.'

y que, además, refuerza a esa otra respuesta previa, que parece rutinaria y solo requiere un proceso de descodificación: ... because I love him.

Así, la argumentación se sitúa en el interior de cada discurso, con un conjunto de estrategias por parte del orador dirigiéndose, con un propósito, hacia un determinado auditorio, y en una situación concreta. El discurso y la textualidad se construyen para ser dirigidos a un ethos. Los diferentes tipos de textos y de discursos se sostienen en una función argumentativa: se narra, se describe, se explica, etc., para sostener una tesis y dirigirla con un propósito al destinatario. En este sentido, Chatman (1991) habla de una «textualidad subordinada». Los tipos de textos se mezclan y se adaptan los unos a los otros, en una relación de subordinación, de forma que cada uno está al servicio del otro. De un texto, se puede decir que en su forma de superficie es una narración, una descripción, etc., pero desde el punto de vista funcional el texto puede estar al servicio de un argumento, por ejemplo. Afirma que algunos géneros (literarios) son más propicios a ponerse al servicio de una ver- 
dad determinada, de una conclusión preconcebida, y de una eventual argumentación. Una narración aparente, de superficie, puede ser sólo un argumento. Él pone como ejemplo la fábula, la cual adopta el modo narrativo para servir a una moral. Las narraciones de hechos por los abogados juegan el mismo rol: son constantemente argumentadas y orientadas. Se trata de una imbricación entre lo narrativo y lo argumentativo.

Sin embargo, nuestro planteamiento es considerar esta textualidad subordinada al servicio de la argumentación, al servicio del discurso argumentativo, el cual, de acuerdo con Virtanen (1992), es un tipo de discurso fuerte, ya que muestra una máxima realización a través de los diferentes tipos de texto. Y en ello basamos nuestra posición: la textualidad ${ }^{12}$ está subordinada a una dimensión del discurso, que es argumentativa. Los distintos tipos de texto (y/o su mezcla) funcionan al servicio de esta dimensión argumentativa. Así, recogiendo la distinción tradicional de la retórica, de cuatro tipos de textos (la argumentación, la descripción, la exposición y la narración), un hablante que transmite una información a su auditorio lo hará codificándola en un tipo o una mezcla de estos tipos de texto. Pero ya hemos visto que esa información se transmite ilocutivamente con una fuerza retórica que se sirve de las formas y estructuras textuales. De modo que la lógica temporal narrativa (o cronológica narrativa), la reproducción descriptiva de algo, la exposición explicativa, estarían subordinadas a una dinámica interaccional de los interlocutores, es decir, a una dimensión argumentativa del discurso.

Y éste estar al servicio de, sería:

a) Una subordinación explícita, claramente, donde la dimensión argumentativa se sirve de tipos, o mezcla de tipos, textuales.

b) O una subordinación implícita, de manera indirecta, con lo que podría tener un mayor grado de ostensión y de inferencia en la acción discursiva.

Así, el texto $\mathrm{n} .^{\circ} 1$ muestra la subordinación explícita de unas estructuras narrativas a los movimientos argumentativos del discurso:

The background: this kid's eighteen years old, 29 points a game, honorable mention in the All-American team. The kid was in reform school, he had gotten into trouble before and he got another chance. He came from a typical

${ }^{12}$ La misma afirmación se puede hacer de la intertextualidad. 
background. His mother was a drug addict, his father was shot when he was three years old and killed by his mother's boyfriend. Supposedly, the kid had turned himself around, became an honors student, top 10 per cent of his class, he'd taken advanced placement courses, had met President Bush when Bush went to speak at his school, he was one of the top 10 kids in the whole school.

$\rightarrow$ [So what happens to this kid?. He's all set to go to Ohio University on a full scholarship, which - how many people in this country can afford that type of tuition?

$\rightarrow$ And what happens? He gets busted for selling crack. Now that's not bad enough, it's stupid enough. His reason for selling crack was that he had to pay for abortions for both of the young women who were impregnated by him.

$\rightarrow$ Well, that's the only good thing he did was he paid for abortions. Better that they had the abortions than produce other anti-social, miscreant prime like him].

Pero, por otra parte, el texto $n .^{\circ} 2$ nos muestra una subordinación implícita (menos clara y con menos, o ningunos, marcadores textuales) de unas estructuras explicativas a los movimientos argumentativos del discurso:

Clean trout, scale \& remove fins, tails, etc. Do not split open. Dip all over in seasoned oatmeal. Heat some butter in a large frying pan. When hot put in trout and fry until golden brown. Cut parsley finely and quarter the lemons. Sprinkle generously over the trout and serve with creamed potatoes and mushrooms.

$\rightarrow$ [So you will have a delicious Ribble valley fried trout].

En la tradición clásica la función de la argumentación ha sido considerada como la acción de convencer a los otros de la verdad o aceptabilidad del discurso que se pretende. Y se puede afirmar que, históricamente, la preocupación por los efectos de cualquier tipo de discurso sobre el auditorio, es una preocupación por la acción argumentativa.

Eemeren et al. (1997: 226), dentro del estudio de las aplicaciones prácticas de la argumentación, proponen tres (o más) objetivos científicos: 1) prescriptivo (llegar a un conjunto de principios que diga a la gente cómo argumentar bien); 2) descriptivo (llegar a un modelo, empíricamente, correcto de discurso argumentativo) y 3 ) crítico (desarrollar un sistema para la evaluación y mejora de las prácticas argumentativas). Y además, plantean dos clases principales de aplicaciones. Una pedagógica, sobre el desarrollo de la competencia argumentativa (orientada no a ganar debates, sino hacia una 
resolución racional de éstos) y que tiene que ver con un reciclamiento de la retórica clásica. Y otra, aplicada al diseño de los procesos de discurso relacionados con los sistemas de comunicación sociales (para un desarrollo de autorregulación de las capacidades de los procesos de argumentación y corrección de obstáculos en la discusión racional). Entre los tres objetivos que proponen, nos interesa destacar la perspectiva descriptiva, donde ellos exponen tres áreas que nos parecen fundamentales para situar el discurso argumentativo:

a) El campo de Conversation Analysis, donde hay ya un flujo de trabajo al respecto (Coulter, 1990; Goodwin, 1983; Jacobs y Jackson, 1982; Schiffrin, 1984).

b) La lógica formal moderna y la ciencia cognitiva, que se ha preocupado recientemente por la descripción de los procesos naturales inferenciales.

c) El estudio experimental de la influencia social, mayormente orientada a identificar qué factores realmente influyen en la gente cuando están ante textos argumentativos (Eagly y Chaiken, 1993; O'Keefe, 1990).

\section{INFORMACIÓN, PERSUASIÓN, DEMOSTRACIÓN}

Entendemos que informar, persuadir y demostrar son tres acciones o campos discursivos de relevancia en la práctica diaria de la lengua, que están situados dentro de la dimensión del discurso argumentativo y su heterogeneidad. Y aunque se pueda afirmar, tal como lo hace Martinich (1984), lo siguiente:

As «arguing» is the name of an illocutionary act, so «persuading» is the name of its correlative perlocutionary act (Martinich, 1984: 96).

nosotros entendemos que informar, persuadir y demostrar forman parte del complejo acto ilocutivo de la argumentación, pero con sus matices propios en sus correspondientes actos perlocutivos.

El discurso es primariamente argumentativo, y su dimensión informativa es secundaria con respecto a su argumentatividad. Con ello no queremos plantear niveles del uso de la lengua, siendo uno superior al otro, sino que la funcionalidad de la lengua es primariamente argumentativa, y que lo informativo o referencial cumple su función de acuerdo con esta funcionalidad argumentativa. El lenguaje funciona retóricamente, y lo referencial e infor- 
mativo está al servicio de lo retórico-argumentativo. Una argumentación puede estar constituida por una simple exposición de hechos, para luego emitir un juicio o hacer una evaluación; orientando, así, el discurso hacia una conclusión. Ducrot (1980: 15) afirma que en un enunciado, los diversos morfemas, expresiones o giros que lo conforman, además de añadir un contenido informativo, sirven para dar al enunciado una orientación argumentativa y para encaminar al destinatario en una u otra dirección (y de ahí su valor argumentativo). Anscombre y Ducrot (1988: 169, y sigs.) muestran cómo lo informativo es un derivado delocutivo ${ }^{13}$ de lo argumentativo: la informatividad está en un segundo lugar en relación a la argumentatividad, ya que la descripción de la realidad no es más que un disfraz de una pretensión mucho más fundamental que es ejercer presión sobre las opiniones del otro. Para ellos, la lengua es fundamentalmente argumentativa, y los valores informativos que puedan aparecer a nivel discursivo son derivados de estas indicaciones argumentativas fundamentales. Anscombre y Ducrot (1988) estudian la argumentación en la lengua desde una perspectiva lingüística y pragmática. Ellos hablan de la «orientación argumentativa» del uso de la lengua, basada en la noción de enunciado ${ }^{14}$, donde se puede distinguir, desde un punto de vista semántico, un contenido informativo o proposicional, pero sin embargo, en el nivel pragmático, este enunciado tiene un valor ilocutivo que hace de él un acto de lengua. Así ellos afirman:

El sentido de un enunciado comporta, como parte integrante, constitutiva, esta forma de influencia que se llama la fuerza argumentativa. Significar, para un enunciado, es orientar. De manera que la lengua, en la medida en la que ella contribuye en primer lugar a determinar el sentido de los enunciados, es uno de los lugares privilegiados donde se elabora la argumentación (Anscombre y Ducrot, 1988: 5 -traducción nuestra-).

Larkin y O'Malley (1973) en su tratamiento de los actos de habla declarativos muestran, también, cómo lo informativo es un derivado ilocutivo de lo argumentativo. Y ésta es también una cuestión clásica entre dos posiciones. La posición descriptiva de la lengua, que mantiene que al hablar se construye una representación, haciendo alusión a un mundo real o ficticio. Es decir, a la lengua se le atribuye, principalmente, una función descriptiva, don-

\footnotetext{
${ }^{13}$ La delocutividad es una noción originada en Benveniste, refiriéndose a un tipo de derivación que ocurre en las expresiones lingüísticas (léxica, semántica, etc.). Ver Anscombre (1979, 1980, 1981).

${ }^{14} \mathrm{El}$ concepto de enunciación viene constituido por la manifiesta presencia del emisor, mientras que el concepto de pragmática (del griego pragma -acción-) lo constituye la acción que se intenta ejercer sobre el receptor.
} 
de lo argumentativo es sobreañadido al valor descriptivo-informativo de la lengua. Y la posición ascriptivista que mantiene que cuando se habla se pretende compartir unas representaciones o unas opiniones, y se pretende, también, conseguir o aumentar la adhesión del oyente o de un auditorio a las tesis que se presentan. Es decir, a la lengua se le atribuye, principalmente, una función retórico-argumentativa, donde lo informativo es derivado de su valor argumentativo: los datos argumentativos son prioritarios para la construcción del sentido de un enunciado.

Entendemos, pues, que la acción de informar es intrínseca a la argumentación. El uso de la lengua, el discurso, es argumentativo, pero informa para conseguir sus propósitos, y lo hace dentro de un marco retórico. De modo que la acción de informar es una acción subordinada al carácter argumentativo del discurso. Y, por lo tanto, también a las acciones argumentativas de demostrar y persuadir. Además, esta acción subordinada de informar utiliza, a su vez, como recursos, otras acciones tales como narrar, describir, explicar, instruir, etc.

Así, en el texto n. ${ }^{\circ}$ 3, Hamish basa todo su movimiento argumentativo en una estructura inicial con una función informativa relevante:

HAMISH: Anyone involved in politics over the past twenty years has got used to being upstaged by a woman...

pero esta función informativa tiene su razón de ser en la orientación argumentativa que tiene dentro del marco de la acción ilocutiva de Hamish con respecto a su auditorio:

$\rightarrow$...But I didn't expect it to happen to me on my wedding day.

$\rightarrow$ However I must also say that I'm quite happy to be upstaged by this woman for the rest of my life.

Con las acciones argumentativas de informar, demostrar y persuadir, podemos hablar del campo de la argumentación, es decir, el campo del discurso y del texto ${ }^{15}$, situado siempre entre las posiciones de los interlocutores. Y que puede ser definido por un flujo entre tres acciones que se dirigen a un tipo de auditorio (Perelman y Tyteca, 1989: 47 y sigs.): demostrar, argumentar (convencer) y persuadir.

15 En cuanto que la noción de campo la podemos identificar con acción, vendría bien recordar a Enkvist (1991: 13), quien compara el texto con «un campo de batalla después de la batalla», y el discurso con «la batalla misma». 
De manera que, en la figura 2, el campo de la argumentación queda representado por un ribete, donde, desde la acción de argumentar, fluyen las acciones de demostrar y persuadir, estando subordinada a todas ellas la acción de informar:

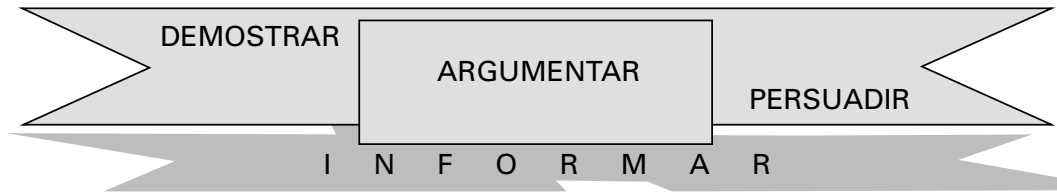

CAMPO DE LA ARGUMENTACIÓN

FIGURA 2.

Por consiguiente, el campo de la argumentación puede ser definido, en la heterogeneidad discursiva, por la propia acción de argumentar (centrada en convencer ${ }^{16}$ ), fluyendo, dentro de esta misma acción, las acciones de demostrar y persuadir. Subordinada a todas ellas, en la sombra, está la acción de informar, con sus estrategias narrativas, descriptivas, explicativas, procedimentales, etc. Se trata, de un campo situado en el diálogo con el auditorio. Donde la acción central de convencer la entendemos como una acción amplia, que abarca no sólo el propio acto de convencer, sino también el mantenimiento de una ideología ${ }^{17}$ o una posición. Así, por ejemplo, en el texto n. ${ }^{\circ} 3$, Hamish pretende, de forma relevante, que su auditorio quede más convencido de algo que ya se supone: I love this woman and I'll do it for the rest of my life. Y para ello, se sirve de un proceso ostensivo-inferencial dejando a su auditorio que infiera esta relevancia:

Anyone involved in politics over the past twenty years has got used to being upstaged by a woman. $\rightarrow$ But I didn't expect it to happen to me on my wedding day. $\rightarrow$ However I must also say that I'm quite happy to be upstaged by this woman for the rest of my life. $\rightarrow$ [I love this woman and I'll do it for the rest of my life].

${ }^{16}$ La dimensión argumentativa se coloca sobre la comunicación que establece el orador tratando de convencer al auditorio sobre unos valores bien fundamentados (Perelman y Tyteca, 1990: 129).

${ }^{17}$ Simpson (1993) define así este concepto: «From a critical linguistic perspective, the term normally describes the ways in which what we say and think interacts with society. An ideology therefore derives from the taken-for-granted assumptions, beliefs and value-systems which are shared collectively by social groups. And when an ideology is the ideology of a particularly powerful social group, it is said to be dominant» (Simpson, 1993: 5). 
Estas tres acciones de argumentar, demostrar y persuadir ${ }^{18}$ :

a) Están dirigidas a: un auditorio universal (demostrar) ${ }^{19}$; unos auditorios particulares - pretendiendo, a menudo, un auditorio universal - implicados en la búsqueda de lo preferible (argumentar); y otros auditorios particulares - de acuerdo con unos objetivos - que son más bien pasivos (persuadir).

b) Construyen una realidad: mediante una lógica formal que excluye las ambigüedades (demostrar); mediante unos razonamientos dialécticos no desprovistos de ambigüedades y que ponen en acción unos juicios de valor (argumentar); mediante la sugestión o la manipulación (persuadir).

c) Utilizan unos medios: de razonamiento impersonales y apremiantes dirigidos al entendimiento mediante el dominio o posesión de la verdad, por lo que una sola prueba puede ser decisiva (demostrar); de razonamiento no impersonales y no apremiantes dirigidos al entendimiento mediante la convicción racional y el dominio de la opinión y de lo probable, lo que conlleva una argumentación más o menos abundante (argumentar); de todo tipo, incluso los irracionales, donde el ethos -el emisor y su imagen - juegan un papel esencial (persuadir). Y podemos observar cómo el valor de la presencia del ethos va creciendo hasta la acción de persuadir, donde esta presencia puede estar materializada por elementos semióticos, más bien que personales, como es el caso de la publicidad en los medios de comunicación de masas.

De esta forma, el campo argumentativo puede trazarse a través del texto, considerando a éste: a) como el lugar de diálogo entre interlocutores; b) de acuerdo con el tipo de auditorio al que se dirija, el tipo de realidad que construya, los medios que utilice, y los propósitos determinados que pretenda.

18 Estas distinciones están basadas en el esquema de Boissinot (1992: 8), distinguiendo demostrar, argumentar y persuadir, según la perspectiva de Perelman y Tyteca $(1989,1990)$

19 Perelman y Tyteca (1989) plantean la necesidad de un auditorio universal, entendido como un auditorio ideal, donde todo el mundo sería convencido de la misma manera y de forma objetiva, rigurosa, científica y racional, excluyendo el ethos y el pathos. Es decir, el auditorio ideal es el auditorio que se enfrenta a una demostración. Pero, generalmente, el auditorio cuenta con unos caracteres subjetivos y diversos que lo hacen particular. 


\section{Persuasión}

La argumentación no es equivalente a discusión ${ }^{20}$ (o inclusive, a debate), pero sí al contrario. La discusión ${ }^{21}$ es una acción más de la argumentación. Igualmente, la argumentación no es equivalente a persuasión, pero sí al contrario. Es decir, la persuasión es una acción o campo más de la argumentación. Meiland (1989; en Golder, 1996: 93), por ejemplo, distingue entre argumentación como persuasión y argumentación como explicación. La explicación, creemos, que puede ser un campo de razones para llegar a una conclusión. Y es un campo orientado a la formación de actitudes y al cambio de creencias, cuyo análisis es ampliamente indiferente al problema de la invención de mensajes persuasivos (O'Keefe, 1990, Eagly y Chaiken, 1993; en Eemeren et al. 1997: 213). Sin embargo, en las situaciones persuasivas puede importar más el propósito del discurso, que el buen fundamento de éste. Y en este aspecto, Golder y Coirier (1996: 272) diferencian a la persuasión de la argumentación:

Thus argumentation and persuasion differ in terms of purpose rather than discourse. In persuasion, language is used to instigate an action; in argumentation it is used to act upon representations (Golder y Coirier, 1996: 272).

Pero la persuasión ha sido identificada con la retórica ${ }^{22}$ y la argumentación $^{23}$. La retórica ha sido considerada, tradicionalmente, como el «arte de

20 «Yet argument, like Rhetoric, often has a bad name. Argument is often seen in a negative way. Among the most dismissive assumptions about the nature of argument are those which are associated with 'rows' or 'disputes'. [...] To be 'argumentative' means to look for trouble, or even to pick fights. An unhappy relationship is one in which the parties are 'always arguing' - and the arguing only makes matters worse. It is a sign that the relationship has failed. [...] A second kind of assumption about argument concerns the making of a case. Terms such as 'bias', 'pressure', and 'manipulation' are used. This assumption contrasts biased comment unfavourably with an ideal of objective reporting or scientific analysis. The most spectacular villain in this scenario is called 'propaganda'. On the other hand, it is right to be 'objective', 'impartial' and 'sincere'. [...] Third, in another view of argument, it is often assumed that time is wasted by formal procedures of debate. Many ready phrases illustrate this attitude: 'to make a debatable point', to be 'contentious'. The phrase 'for argument's sake' can mean that something is not meant 'seriously’» (Leith y Myerson, 1989: 81-82).

${ }^{21}$ Ducrot (1984: 30) afirma que la dimensión argumentativa manifiesta la función erística de la lengua.

22 Tradicionalmente, las etapas en el proceso de persuadir eran las mismas que para la retórica: inventio, dispositio, elocutio, memoria, pronuntatio. Y Aristóteles consagró un tratado entero al arte de la persuasión, el cual exigía el dominio del razonamiento, de las pasiones y del estilo.

${ }^{23}$ Perelman y Tyteca (1989: 67) distinguen entre la argumentación persuasiva, que sólo pretende servir para un auditorio particular, y la argumentación convincente a la que se supone que obtiene la adhesión de todo ente de razón. Aunque ellos afirman que este matiz diferenciador entre persuadir y convencer es impreciso y puede que en la práctica se suprima. «One well-known division of arguments re- 
expresarse y de persuadir»; y la argumentación ha sido identificada en sus objetivos con la persuasión. Su acción, en el quehacer diario, se realiza mayormente a través del discurso oral, y en la comunicación de masas a través de ambas formas: oral y escrita. Esta acción tiene el propósito de lograr una identificación entre hablante y oyente (Burke, 1969) para lograr, en el destinatario, una convicción, una estimulación (actitud emocional), o una actuación. Es, más bien, el modo de esta incitación, a la acción intelectual, emocional o física, lo que caracteriza a la persuasión. Este modo de incitación estaría subordinado a la aportación que puede hacer el hablante sobre el análisis situacional de las reacciones del destinatario. En este ámbito, tradicionalmente desde Aristóteles, se han considerado dos estrategias lingüísticas:

a) El uso de un lenguaje natural y común al destinatario para así establecer un vínculo lingüístico entre ambos interlocutores.

b) El uso de un estilo lingüístico lo suficientemente extraordinario como para atraer la atención del destinatario hacia el lenguaje del hablante, y separarlo de su rutina y lugar o estado habitual.

La tensión adecuada entre estas dos estrategias lingüísticas (tanto en lo escrito como en lo oral) ha constituido el rasgo básico de la persuasión.

Kinneavy (1971: 211-220) distingue al discurso persuasivo ${ }^{24}$ en una clara identificación con la argumentación y la retórica: centrado fundamentalmente en el destinatario e intentando provocar en él una acción, emoción o convicción específica. Él afirma que ninguna área del discurso es inmune a la persuasión. Aunque ésta puede estar en un plano secundario o de una forma indirecta. Además, señala su carácter neutral, ni verdadero ni falso, aunque el tema de que trate pueda ser no verdadero. Y Dijk (1998: 241-254) contempla la persuasión como una estrategia cognitiva y discursiva implicada en la formación y el cambio de las ideologías que resulta de la comunicación verbal.

\footnotetext{
cognizes «forensic» arguments, designed to establish the truth or falsity of allegations about people's conduct and the rightness of judgments about their behavior; «deliberative» arguments, designed to establish the desirability of taking or not taking particular actions; and «epideictic» arguments, designed to demonstrate that someone deserves honor and praise. All of these forms of arguments have in common the desire to persuade by means of discourse» (Fahnestock y Secor, 1982: vii).

${ }^{24}$ Kinneavy (1971) distingue entre discurso expresivo (centrado en el codificador), discurso persuasivo (centrado en el descodificador), discurso referencial (centrado en representar o reproducir la realidad) y discurso literario (centrado en el texto como forma lingüística o código).
} 
Por consiguiente, la persuasión es un campo de la argumentación, caracterizado por su propósito comunicativo: pretende que el otro interlocutor renuncie a su posición y se sitúe en la posición de quién persuade:

It is not reality that is altered by its description, rather is it the interlocutor's outlook on reality and his/her interpretation that can be controlled by devices of persuasive communication (Sornig, 1989: 96).

Según Sornig (1989) para que haya persuasión debe de haber «inteligibilidad». Es decir, para que la lengua sea efectiva en el acto de comunicación persuasiva, la persona que va a ser convencida debe de entender toda la información y todo el significado asociativo que le está siendo transmitido. Ello significa que debe de haber un paralelismo entre ambos interlocutores, además de entre los conocimientos de fondo, con respecto a los rasgos referenciales-denotativos, los grados de intensidad semántica y expresividad, y, sobre todo, con respecto al significado connotativo, aspectos actitudinales, expectativas y miedos.

Sornig (1989): a) limita el campo de la persuasión y b) caracteriza unos rasgos lingüísticos en las estrategias persuasivas. Tanto la limitación como la caracterización de estos rasgos lingüísticos nos parecen muy interesantes, aunque no exclusivos al cien por cien de este campo:

a) Así, el acto de habla persuasivo (o campo de la persuasión) se caracteriza por: la retirada de la condición de sinceridad, y por el acto de impresionar y sorprender a alguien. Y se diferencia de:

- La adulación, donde el receptor es convencido de que su interlocutor ha renunciado a su punto de vista a favor del suyo.

- La seducción, que es intentar que el receptor actúe o haga cosas como si se tratara de su propio impulso, pero que realmente es por instigación desde fuera de él. E implica un importante movimiento: que la persona en cuestión se mire a sí mismo, pero que mire a las cosas desde otro ángulo aparentemente más agradable, lo cual significa un cambio de perspectiva.

- El convencimiento, que trabaja principalmente a través de las líneas cognitivas argumentativas, y confía en la verdad y credibilidad de los argumentos.

Pero, señala Sornig, el convencimiento es el primer objetivo de la persuasión. Este convencimiento depende del paralelismo de presunciones, ex- 
pectativas y aversiones, $\mathrm{y}$ del significado referencial, asociativo y afectivo, $\mathrm{y}$ consecuentemente se supone que lleva a una conducta activa, coordinada y similar.

Sin embargo, creemos que establecer un límite entre estos campos es imposible. Y lo más frecuente es que se realicen de una forma mezclada, al igual que la heterogeneidad en un texto o un discurso.

b) De la misma forma, no podemos limitar la caracterización de los rasgos lingüísticos que Sornig hace de la persuasión sólo a éste campo. Entendemos que son estrategias lingüísticas en el uso de la lengua para lograr unos propósitos comunicativos, que pueden ser persuasivos o no, pero que ante todo son retóricos, con un determinado grado de fuerza retórica de acuerdo con la situación en la que se utiliza (ver Carrillo, 2006). Nos parece interesante enumerar estas estrategias:

- Citaciones, para explotar el prestigio de la persona que origina la citación, o para abusar de lo que alguien de importancia ha dicho.

- Estructuras marcadas para aumentar la atención y crear sorpresa, y dar al receptor el sentimiento de que está tomando parte de algo extraordinario. Utilizadas mucho en el campo de la publicidad. Estructuras morfológicas y derivativas, caracterizadas como graciosas, extravagantes y novedosas, están en boga en este campo.

- Reactivación, innovación, e incluso invención de modelos morfológicos, especialmente derivativos.

- El uso del tiempo de presente como tópico (topicalidad), muy extendido en el lenguaje periodístico, donde sirve para deslizar las dimensiones temporales de la perspectiva del receptor. Similares efectos de algo inusual o marcado, resultan del uso de los tiempos del infinitivo o participio perfecto, donde se hubiera esperado un imperativo o un tiempo narrativo.

- El cambio de categoría gramatical es otro recurso para la creación de sorpresa. Por ejemplo, el uso de morfemas en categorías diferentes de las que el receptor hubiera esperado.

- El camuflar la acción de un autor, o disminuir la credibilidad de un asunto, mediante el uso de la voz pasiva, es logrado también mediante el uso del modo subjuntivo (estilo indirecto).

- El uso de expresiones tautológicas, que siempre tienen un efecto agresivo, y que son muy utilizadas en publicidad. 
- El eufemismo, que es la manipulación parafrástica en el nivel del léxico, donde las palabras son reemplazadas por otras cuyos componentes evaluativos son más agradables. El eufemismo, al igual que la manipulación parafrástica en general, es motivada por la presunción de que un cambio de nombre puede suponer cualidades nuevas y diferentes para una persona o cosa.

- Reemplazar el significado concreto de una palabra por otro cuyo significado es más genérico (es una estrategia manipulativa similar al eufemismo). Se trata de una desconcretización como resultado de un desinflamiento del contenido referencial (y connotativo), y por lo tanto puede servir como un camuflaje semántico.

- La creación de un ambiente de afabilidad y de propósitos compartidos, mediante elementos léxicos que apelan a las emociones del receptor, y especialmente aquellos con referencia al orgullo nacional, sexual, a la agresividad, etc.

- El empleo repetido de expresiones, en situaciones que, aunque aparentemente divergentes, tienen una carga afectiva similar, y logrando que el significado denotativo de estas expresiones afectivas llegue a ser cada vez más obscurecido y borroso, mientras que sus convenciones connotativas están consolidadas.

- El uso de ambigüedades, especialmente juegos de palabras, que crean sorpresa y activan la competencia de descodificación del receptor para extraer el significado y la intención del emisor.

- El efecto producido por un léxico específico sobre actitudes y conductas evaluativas, y respuestas emocionales.

- La invención y uso de neologismos, que crea una apariencia de algo extraordinario, lindando con una inteligibilidad científica, como sucede con lexemas de origen extranjero.

- La insinuación de afabilidad, creando un ambiente de destino mutuamente compartido al simular unas variantes de habla que connotan intimidad.

Entendiendo que el uso persuasivo de la lengua no apela tanto a la razón como a las expectativas y emociones del destinatario (Sornig, 1989) vemos que las transformaciones semánticas y la manipulación del significado, que estas estrategias lingüísticas realizan, muestran cómo la dimensión argumentativa de la lengua puede ser explotada por una lógica tan efímera e ines- 
table como es la lógica de las emociones ${ }^{25}$ y de las expectativas humanas. Pero en todo ello, como en toda argumentación o toda conducta lingüística, hay un proceso de convicción ${ }^{26}$. Así, el discurso del texto n. ${ }^{\circ} 4$, emocionalmente, crea unas expectativas (...take advantage of these benefits...) que pueden no serlo en cualquier momento.

\section{Demostración}

La demostración es un encadenamiento deductivo de proposiciones, que puede ser considerado como un campo más de la argumentación. Entendemos que ésta puede tener un carácter formal o bien un carácter más informal y retórico. Formalmente, su particularidad consiste en que transfiere en su movimiento argumentativo, de las premisas a la conclusión, una propiedad objetiva y verdadera, centrándose más en este proceso que en la adhesión del auditorio, ya que éste se adhiere de una forma objetiva ${ }^{27}$ y no mediante una adhesión relativa más o menos intensa (Perelman, 1983: 173). Perelman (1982: 47) hace una clara distinción entre argumentación y demostración en tres aspectos importantes:

- Primero, la demostración solamente es posible dentro de un sistema formal de axiomas y reglas de influencia. En cambio, la argumentación no parte de axiomas sino de la opinión, de los valores o de los puntos de vista discutibles. La argumentación hace uso de inferencias lógicas, pero no exhaustivamente en un sistema deductivo de afirmaciones formales.

- Segundo, una demostración se realiza para convencer a un auditorio específico con un conocimiento específico. Mientras que la argumentación se dirige siempre a un auditorio particular e intentando conseguir la adherencia de los miembros del auditorio a las tesis que se presentan.

25 Ver a Gilbert (2001) para un análisis de los mensajes emocionales (o actos de mensajes emocionales) en la argumentación; y el Principle of Pragmatic Emotionalization, centrado en el rol que la emoción juega en la argumentación.

${ }^{26}$ Según Aristóteles, para convencer a un interlocutor, es necesario poner a éste en tal posición que se encuentre en la imposibilidad de rehusar las proposiciones expuestas. Y para ir en el sentido de tal imposibilidad, es necesario que estas proposiciones sean tan próximas como posibles a alguna opinión o autoridad general.

27 En el campo de una aparente argumentación, en filosofía, se ha cultivado un discurso demostrativo ajustado a un razonamiento matemático. 
- Tercero, la argumentación no pretende conseguir un acuerdo intelectual, sino incitar a la acción o al menos crea una disposición a actuar en el momento apropiado.

Teniendo en cuenta estas afirmaciones, no debemos olvidar que todo texto científico, y por consiguiente objetivo, se construye en la argumentación y en la controversia (Vignaux, 1988: 51); y que una demostración formal puede tener una orientación o uso retórico. Aunque una demostración de tipo lógico-matemático tiene poco que ver con la retórica, y por tanto poco que ver con la argumentación:

...la retórica se ocupa de la organización y preparación de los efectos textuales en una argumentación de convicción y de persuasión (Martínez-Dueñas, 2003: 8).

Sin embargo, una demostración sin ese rigor formal, y desarrollando un discurso racional para convencer al auditorio, tiene una proyección más retórica y, en consecuencia, desarrolla una acción más argumentativa.

La noción de auditorio universal de Perelman y Tyteca (1989) como auditorio medio, ideal, objetivo, puede estar orientada a una argumentación rigurosa ${ }^{28}$, tal como puede ser una demostración de carácter científico, y donde los interlocutores pierden protagonismo o acción en favor de la demostración. Pues el encadenamiento de razonamientos unidos de la demostración es más bien independiente de la voluntad e intención de su autor con respecto al auditorio. Sin embargo, en la argumentación, propiamente dicha, interviene más el carácter retórico de ésta: el orador elige y articula sus argumentos en función de una estrategia con respecto a su auditorio particular y subjetivo. Y, a partir de aquí, se pueden resaltar dos tipos de argumentaciones, que la tradición retórica ha distinguido:

- La argumentación ad rem (sobre la cosa), o ex concessis (por un acuerdo unánime), donde la relevancia la tiene la demostración sobre un acuerdo de creencias comunes entre los interlocutores.

- La argumentación ad hominem (dirigida al hombre) ${ }^{29}$, donde la relevancia la tiene el mensaje y la acción entre los interlocutores.

28 «Una argumentación dirigida a un auditorio universal debe convencer al lector del carácter apremiante de las razones aducidas, de su evidencia, de su validez intemporal y absoluta, independientemente de las contingencias locales o históricas» (Perelman y Tyteca, 1989: 72).

29 «No se debe confundir el argumento ad hominem con el argumento ad personam, es decir, con un ataque contra la persona del adversario y que tiende, principalmente, a descalificarlo» (Perelman y Tyeteca, 1989: 186). 
En esta misma perspectiva de Perelman y Tyteca (1989), Werlich ${ }^{30}$ (1982: 106 y sigs.) distingue dos formas de textos argumentativos: el texto comentario que corresponde a una argumentación basada en un punto de vista subjetivo, y el texto científico que corresponde a una argumentación basada en un punto de vista objetivo.

En la argumentación comentario, el codificador (en el cual hay una intención) desarrolla unos juicios, relacionando conceptos de eventos, objetos, e ideas con sus sistemas privados de pensamiento, valores y juicios. Aquí, Werlich distingue entre comentario breve (en la comunicación hablada: discusiones, debates, entrevistas, comentarios de TV, charlas informales; en la comunicación escrita: declaraciones personales, cartas, comentarios, reseñas de periódicos) y comentario dilatado (comentarios hablados en la radio, artículos escritos de opinión en periódicos y revistas).

En la argumentación científica, el codificador (en el cual hay una intención) desarrolla unos juicios, relacionando conceptos de eventos, objetos e ideas con sistemas de pensamiento y conocimiento para que las proposiciones resultantes puedan verificarse como válidas o hipótesis válidas. Transmitiendo al descodificador nuevas consideraciones acerca de la solución de problemas científicos.

\section{CONCLUSIONES}

La dimensión del discurso argumentativo tiene su presencia en unas estructuras textuales heterogéneas, y se extiende a través de los niveles de: discurso e interacción social y organización pragmática de la textualidad, por todo tipo de texto. Estos dos niveles, en una relación de inclusión (el uno incluye o implica el otro), vienen a actuar en la misma acción discursiva: interviniendo sobre las opiniones, actitudes o comportamientos del interlocutor o de un auditorio, haciendo aceptables o creíbles unas conclusiones que se apoyan sobre unos argumentos, datos o razones. Ello trae consigo que, si se aceptan las conclusiones, estos argumentos, datos o razones también son aceptados.

30 Werlich (1982) tiene en cuenta que los textos se correlacionan distintamente con los factores contextuales en una situación de comunicación, y que éstos, también, se correlacionan con las propiedades biológicas innatas de la mente del comunicante. Él define así la argumentación: «Argumentation is the type of textual communication in which the encoder proposes relations between concepts of phenomena. The encoder makes his propositions in explicit or implicit opposition to deviant or alternative propositions. Argumentation is the text type related to the cognitive process of judging in answer to a problem» (Werlich, 1982: 40). 
Por consiguiente, la dimensión del discurso argumentativo es una dimensión retórica, basada en el principio dialogal de la lengua y en una dinámica de posiciones entre los interlocutores, donde, por medio de un proceso de argumentación (compuesto de un determinado número de argumentos), esta dinámica organiza un tipo de circuito textual, en el cual se puede:

a) Aportar unas informaciones o proponer unas afirmaciones de manera expositiva, y de acuerdo con una progresión de la información.

b) Narrar un proceso de transformación desde un estado inicial a un estado final, mediante unas conexiones temporales.

c) Organizar un texto según unas relaciones demostrativas y lógicas, mediante unos procesos de razonamiento (inducción, deducción, analogía, etc.) y una progresión utilizando unos conectores lógicos.

d) Realizar una intervención de diálogo con un carácter más o menos relevante en una interacción ilocutiva, y con la presencia (de alguna manera) de las voces de refutación, concesión, ironía, etc.

e) Y desarrollar un proceso comunicativo de ostensión y de inferencia en un marco retórico.

La acción y fuerza ilocutiva que despliega un texto narrativo, descriptivo, explicativo, procedimental, etc., viene dada por su dimensión argumentativa y fuerza retórica. En ellos siempre hay una acción argumentativa con un objetivo ilocutivo y una organización pragmático-textual argumentativa. De modo que un texto puede presentar en su superficie una estrategia narrativa, descriptiva, etc., pero en el nivel ilocutivo del discurso siempre hay en ese texto, explícita o implícitamente, una fuerza retórica y argumentativa. Así, la argumentación se sitúa en el interior de cada discurso, con un conjunto de estrategias por parte del orador, dirigiéndose, con un propósito, hacia un determinado auditorio, y en una situación concreta.

Así, las diferentes acciones discursivas, narrativa, descriptiva, explicativa, procedimental, etc., desarrollarán, por cuestión del tipo de género al que pertenecen, unas secuencias textuales y unas funciones propias características de ellas, y ahí se definirían sus respectivas acciones. Pero creemos que todas ellas desarrollan también, de una forma o de otra, una acción ilocutiva, una acción argumentativa (en sus dos niveles, expuestos anteriormente), basadas en las diferentes posiciones o puntos de vista sobre la construcción de la realidad. Por ello, entendemos que estas acciones, correspondientes a unos tipos de textos o de discursos, y a unas estructuras genéricas, en su base, están al 
servicio de una acción mayor, la acción argumentativa. Y teniendo todas ellas una orientación argumentativa.

El campo de la argumentación puede ser definido, en la heterogeneidad discursiva, por la propia acción de argumentar (centrada en convencer), y dentro de esta misma acción fluyen las acciones de demostrar y persuadir. Subordinada a todas ellas, en la sombra, está la acción de informar ${ }^{31}$, con sus estrategias narrativas, descriptivas, explicativas, procedimentales, etc. Se trata de un campo situado en el diálogo con el auditorio. Donde la acción central de convencer la entendemos como una acción amplia, que abarca no sólo el propio acto de convencer, sino también el mantenimiento de una ideología o una posición.

La argumentación no es equivalente a discusión (o inclusive debate), pero sí al contrario. La discusión es una acción más de la argumentación. Y la argumentación no es equivalente a persuasión, pero sí al contrario. Es decir, la persuasión es una acción o campo más de la argumentación. La persuasión es un campo de la argumentación caracterizado por su propósito comunicativo: pretende que el otro interlocutor renuncie a su posición y se sitúe en la posición de quién persuade. Y la demostración es un encadenamiento deductivo de proposiciones, que puede ser considerado, también, como un campo más de la argumentación. Entendiendo que ésta (la demostración) puede tener un carácter formal o bien un carácter más informal y, por tanto, más retórico.

\section{REFERENCIAS BIBLIOGRÁFICAS}

ADAM, J. M. (1985). «Quels types de textes?». Le français dans le monde 192, 39-43. Paris: Hachette.

- (1997). Les textes: types et prototypes. Récit, description, argumentation, explication et dialogue. Paris: Nathan, 3. ${ }^{\mathrm{a}} \mathrm{ed}$.

ANDREws, R. (1992). «Narrative, Argument and Rhetoric». En The Rebirth of Rhetoric. Essays in Language, Culture and Education, R. Andrews (ed.), 116-128. London: Routledge.

Anscombre, J.C. (1979). «Délocutivité benvénistienne, délocutivité généralisée et performativité». Langue Française 42, 69-84.

${ }^{31}$ El discurso es primariamente argumentativo y su dimensión informativa es secundaria con respecto a su argumentatividad. 
- (1980). «Voulez-vous dériver avec moi». Communications 32, 61-124.

- (1981). «Marqueurs et hypermarqueurs de dérivation illocutoire». Cahiers de linguistique française (Université de Genéve) 3, 88 y sigs.

Anscombre, J. C. y Ducrot, O. (1988). L'Argumentation dans la Langue. Liège: Pierre Mardaga Éditeur, 2. ${ }^{\mathrm{a}}$ ed.

ANTAKI, C. (1994). Explaining and Arguing. The Social Organization of Accounts. London: SAGE Publications.

Beale, W. H. (1987). A Pragmatic Theory of Rhetoric. Carbondale and Edwardsville, Ill.: Southern Illinois University Press.

Boissinot, A. (1992). Les textes argumentatifs. Toulouse: Bertrand-Lacoste.

BuRKe, K. (1969). A Rhetoric of Motives. Berkeley/Los Angeles: University of California Press [publicado en 1950].

Carrillo Guerrero, L. (2006). «Fuerza retórica del texto». Analecta Malacitana (Universidad de Málaga) XXIX. 1, 113-137.

Chatman, S. (1991). «Arguments et narrations». En L'Argumentation, A. Lempereur (ed.), 147-152. Liège: Pierre Mardaga Éditeur.

Collinson, D. (1988). «Engineering Humor: Masculinity, Joking and Conflict in Shop-Floor Relations». Organization Studies 9, 181-99.

Coulter, J. (1990). «Elementary Properties of Argument Sequences». En Interaction Competente, G. Psathas (ed.), 181-203. Washington, DC: International Institute for Ethnomethodology and Conversation Analysis, and University Press of America.

DiJk, T. A. van (1997). «The Study of Discourse». En Discourse as Structure and Process. Discourse Studies: A Multidisciplinary Introduction Volume 1, T. A. van Dijk (ed.), 1-34. London: SAGE Publications.

- (1998). Ideology. A Multidisciplinary Approach. London, etc.: SAGE Publications.

Ducrot, O. (1980). Les échelles argumentatives. Paris: Les Éditions de Minuit.

- (1984). Le dire et le dire. Paris: Les Éditions de Minuit.

Eagly, A. H. y Chaiken, S. (1993). The Psychology of Attitudes. Fort Worth, TX.: Harcourt Brace Jovanovich. 
EEMEREn, F. H. van y Grootendorst, R. (1984). Speech Acts in Argumentative Discussions. A Theoretical Model for the Analysis of Discussions Directed towards Solving Conflicts of Opinion. Dordrechts: Foris Publications.

Eemeren, F. H. van; Grootendorst, R.; JaCKSON, S. y JaCobs, S. (1997). «Argumentation». En Discourse as Structure and Process. Discourse Studies: A Multidisciplinary Introduction Volume 1, T. A. van Dijk (ed.), 208-229. London: SAGE Publications.

Enkvist, N. E. (1991). «Discourse Strategies and Discourse Types». En Functional and Systemic Linguistics. Approaches and Uses, E. Ventola (ed), 3-22. Berlin, New York: Mouton de Gruyter.

FAHNESTOCK, J. y SECor, M. (1982). A Rhetoric of Argument. New York: Random House.

FAIGLEy, L. y MeYeR, P. (1983). «Rhetorical Theory and Readers' Classifications of Text Types». Text 3 (4), 305-325.

GILBERT, M. (2001). «Emotional Messages». Argumentation 15 (3), 239-350.

GOLDER, C. (1996). Le développement des discours argumentatifs. Lausanne: Delachaux et Niestlé.

GOLDER, C. y CoIRIER, P. (1996). «The Production and Recognition of Typological Argumentative Text Markers». Argumentation 10 (2), 271-282.

GoodwIN, M. H. (1983). «Aggravated Correction and Disagreement in Children's Conversations». Journal of Pragmatics 7, 657-77.

JACOBS, S. y JACKSON, S . (1982). «Conversational Argument: A Discourse Analytical Approach». En Advances in Argumentation Theory and Research. J. R. Cox y C. A. Willard (eds.), 205-237.Carbondale and Edwardsville, Ill.: Southern Illinois University Press.

Kinneavy, J. L. (1971) (publicación por Norton: 1980). A Theory of Discourse. New York, London: Norton \& Company.

Kress, G. (1989). Linguistic Processes in Sociocultural Practice. Oxford: Oxford University Press.

LARKIN, D. y O'MALley, M. (1973). «Declarative Sentences and the Rule-ofConversation Hypothesis». En Papers from the Ninth Regional Meeting, 201-20. Chicago: Linguistic Society. 
Leith, D. y Myerson, G. (1989). The Power of Address. Explorations in Rhetoric. London, New York: Routledge.

Lo Cascio, V. (1998). Gramática de la Argumentación. Madrid: Alianza Editorial (Versión española de David Casacuberta de Grammatica dell'argomentare. Strategie e strutture. Scandicci (Firenze): La Nuova Italia Editrice, 1991).

MARTínez-DueÑAs, J. L. (2002). Retórica de la lengua inglesa. Granada: Comares.

- (2003). El Verbo con Sentido. Diálogo sobre la Retórica y su actualidad. Granada: Grupo \&.

Martinich, A. P. (1984). Communication and Reference. Berlin, New York: Walter de Gruyter.

MeILAND, J. W. (1989). «Argument as Inquiry and Argument as Persuasion». Argumentation 3, 185-196.

Moeschler, J. (1985). Argumentation et conversation. Eléments pour une analyse pragmatique du discours. Paris: Hatier-Credif.

Mumby, D. K. 1987. «The Political Function of Narrative in Organizations». Communication Monographs 54, 113-27.

- (1988). Communication and Power in Organizations: Discourse, Ideology and Domination. Norwood, NJ.: Ablex Publishing Corporation.

Mumby, D. K. y ClaiR, R. P. (1997). Organizational Discourse. En Discourse as Social Interaction. Discourse Studies: A Multidisciplinary Introduction Volume 2, T. A. Dijk van (ed.), 181-205. London: SAGE Publications.

Nielsen Ellerup, A. (1996). «The Argumentative Impact of Causal Relations - An Exemplary Analysis of the Free Predicate in the Promotional Discourse». Argumentation 10 (3), 329-345.

O'KeEFE, D. J. (1990). Persuasion: Theory and Research. Thousand Oaks, CA.: SAGE Publications.

Perelman, C. (1982). The Realm of Rhetoric. Notre Dame: University of Notre Dame.

- (1983). «Logique formelle et argumentation». En Logique, argumentation, conversation: Actes du Colloque de Pragmatique, Fribourg, 1981, 
P. Bange, A. Bannour, A. Berrendonner, O. Ducrot, C. Kohler-Chesny, G. Lüdi, Ch. Perelman, B. Py, E. Roulet (eds.), 159-187. Berne: Peter Lang.

Perelman, C. y Olbrechts-Tyteca, L. (1989). Tratado de la argumentación. La nueva retórica. Madrid: Gredos (Traducción de Julia Sevilla de Traité de l'árgumentation. La nouvelle rhetorique, Bruxelles: Editions de l’Université de Bruxelles, 1976).

- (1990). «Nouvelles rhétorique-Logique et rhétorique». En L'home et la rhétorique, A. Lempereur (ed.), 117-151. Paris: Méridiens Klincksieck.

POPPER, K. (1972 /1979). Objective Knowledge. Oxford: Oxford University Press, $2{ }^{a}$ ed.

SCHIFFRIN, D. (1984). «Jewish Argument as Sociability». Language in Society 13, 311-36.

Simpson, P. (1993). Language, Ideology and Point of View. London, New York: Routledge.

SorNIG, K. (1989). «Some Remarks on Linguistic Strategies of Persuasion». En Language, Power and Ideology. Studies in Political Discourse, R. Wodak (ed.), 95-115. Amsterdam, Philadelphia: John Benjamins.

Toulmin, S. (1958). The Uses of Argument. Cambridge: Cambridge University Press (2. ed. 1969; reimpreso: 1986).

Vignaux, G. (1988). Le Discours acteur du monde. Enonciation, argumentation et cognition. Paris: Ophyrs.

VIRTANEN, T. (1992). «Issues of Text Typology: Narrative - a «Basic» Type of Text?». Text 12 (2), 293-310.

Werlich, E. (1982). A Text Grammar of English. Heidelberg: Quelle \& Meyer (1. ed. 1976). 